\title{
Developing a method to assess risks and unsafety in drilling - blasting activities at limestone quarries in Lao PDR
}

\author{
Phonepaserth Soukhanouvong ${ }^{1}$, Hieu Quang Tran ${ }^{2,}{ }^{*}$, Hoa Thu Thi Le ${ }^{2}$, Thao Qui \\ $\mathrm{Le}^{2}$, Hoan Do Ngoc ${ }^{2}$
}

${ }^{1}$ Department of Energy and Mines of Bolikhamxay, Bolikhamxay, Lao PDR

${ }^{2}$ Hanoi University of Mining and Geology, Hanoi, Vietnam

\begin{tabular}{|c|c|}
\hline ARTICLE INFO & ABSTRACT \\
\hline $\begin{array}{l}\text { Article history: } \\
\text { Received 08 } 08^{\text {th }} \text { May } 2021 \\
\text { Revised 09th Aug. } 2021 \\
\text { Accepted } 11^{\text {th }} \text { Sept. } 2021\end{array}$ & $\begin{array}{l}\text { Currently, the demand for stone construction materials in Lao PDR to serve } \\
\text { industrial and traffic works is very large. Currently, the management of } \\
\text { mining activities at limestone quarries in Lao PDR is facing many difficulties } \\
\text { due to the existence of many types of mines, mining technologies, and }\end{array}$ \\
\hline $\begin{array}{l}\text { Keywords: } \\
\text { Construction materials, } \\
\text { Drilling - blasting, } \\
\text { Lao PDR, } \\
\text { Limestone quarry. }\end{array}$ & $\begin{array}{l}\text { equipment. The occupational safety and environmental protection used at } \\
\text { the limestone quarries have not been paid due attention. The loss and waste } \\
\text { of natural resources are increasing. In particular, labor accidents caused by } \\
\text { unsafe drilling and blasting activities often occur at the limestone quarries } \\
\text { of construction materials in all provinces of this country. The article } \\
\text { analysed the current situation of drilling and blasting activities at the } \\
\text { limestone quarries of construction materials of Lao PDR, thereby proposed } \\
\text { a method to assess risks and unsafety in drilling and blasting activities at } \\
\text { the limestone quarries for mining the construction materials to improve the } \\
\text { efficiency of the mining management and safety in Lao PDR. }\end{array}$ \\
\hline
\end{tabular}

Copyright (C) 2021 Hanoi University of Mining and Geology. All rights reserved.

${ }^{*}$ Corresponding author

E - mail: tranquanghieu@humg.edu.vn

DOI: $10.46326 / J M E S .2021 .62$ (5).08 


\title{
Xây dựng phương pháp đánh giá nguy cơ rủi ro, mất an toàn trong hoạt động khoan - nổ mìn tại các mỏ khai thác đá vôi tại nước CHDCND Lào
}

\author{
Phonepaserth Soukhanouvong 1, Trần Quang Hiếu 2,*, Lê Thị Thu Hoa 2, Lê Quí \\ Thảo ${ }^{2}$, Đỗ Ngọc Hoàn ${ }^{2}$
}

1 Sở Năng lượng và Mỏ tỉnh Bolikhamxay, Bolikhamxay, CHDCND Lào

${ }^{2}$ Trường Đại học Mỏ - Địa chất, Hà Nội, Việt Nam

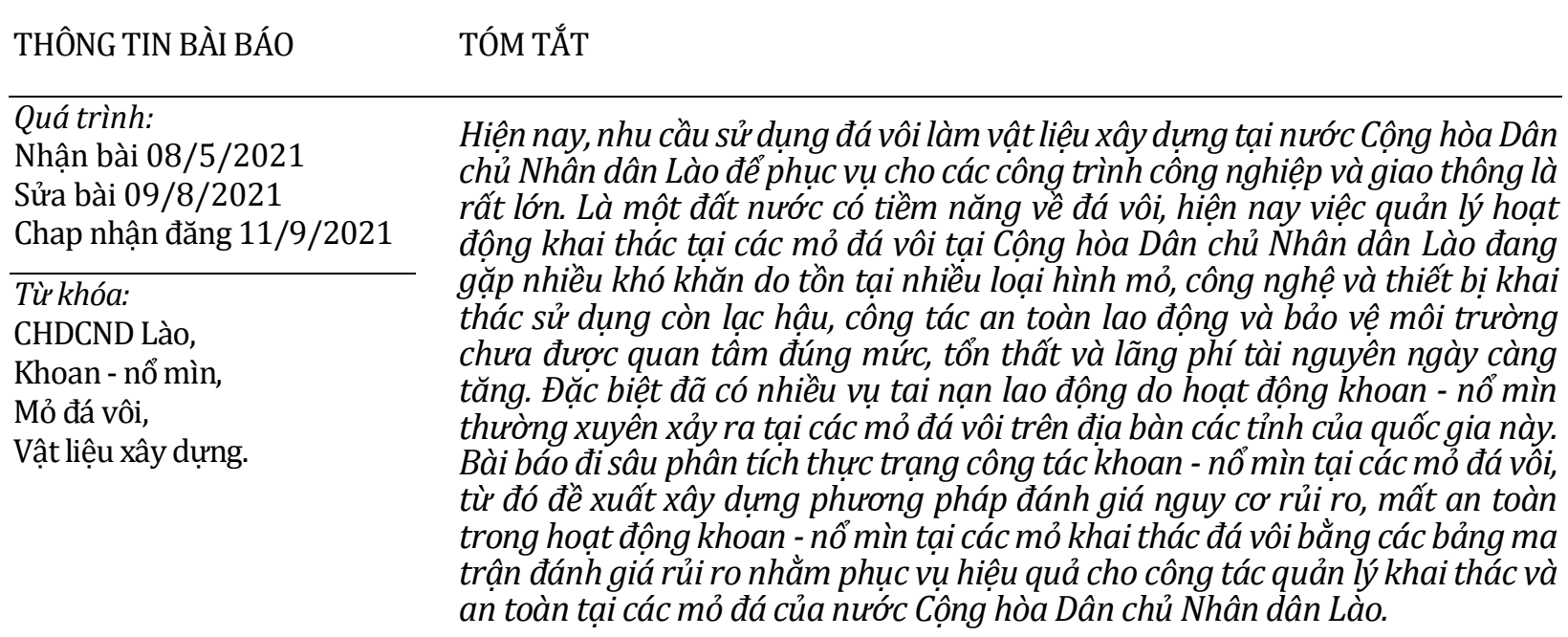

C 2021 Trường Đại học Mỏ - Địa chất. Tất cả các quyền được bảo đảm.

\section{Mở đầu}

Cộng hòa Dân chủ Nhân dân Lào (CHDCND Lào) là một quốc gia thuộc Đông Nam Á, phía bắc giáp Trung Quốc với 416 km đường biên giới, phía tây bắc giáp Myanmar (Miến Điện) với $230 \mathrm{~km}$ đường biện, phía tây nam giáp Thái Lan với 1.730

\section{*Tác giả liên hệ}

$E$ - mail: tranquanghieu@humg.edu.vn

DOI: 10.46326/JMES.2021.62 (5).08 km đường biện, phía nam giáp Campuchia với 492 $\mathrm{km}$ và phía đông giáp Việt Nam với 2.067 km đường biên. CHDCND Lào có diện tích 236.800 $\mathrm{km}^{2}$, dân số hơn 7 triệu người, trong nước có nhiều mỏ khai thác đá vôi để phục vụ cho các công trình xây dựng và nhà máy xi măng trong nước (Hình 1) (Soukhanouvong, 2019). Đá vôi ở CHDCND Lào là một loại đá trầm tích, về thành phần hóa học chủ yếu là khoáng vật canxit và aragonit (các dạng kết tinh khác nhau của cacbonat canxi $\mathrm{CaCO}_{3}$ ). Đá vôi ở đây ít khi ở dạng tinh khiết mà thường bi lẫn các tạp chất như đá phiến silic, silica và đá mácma cũng 


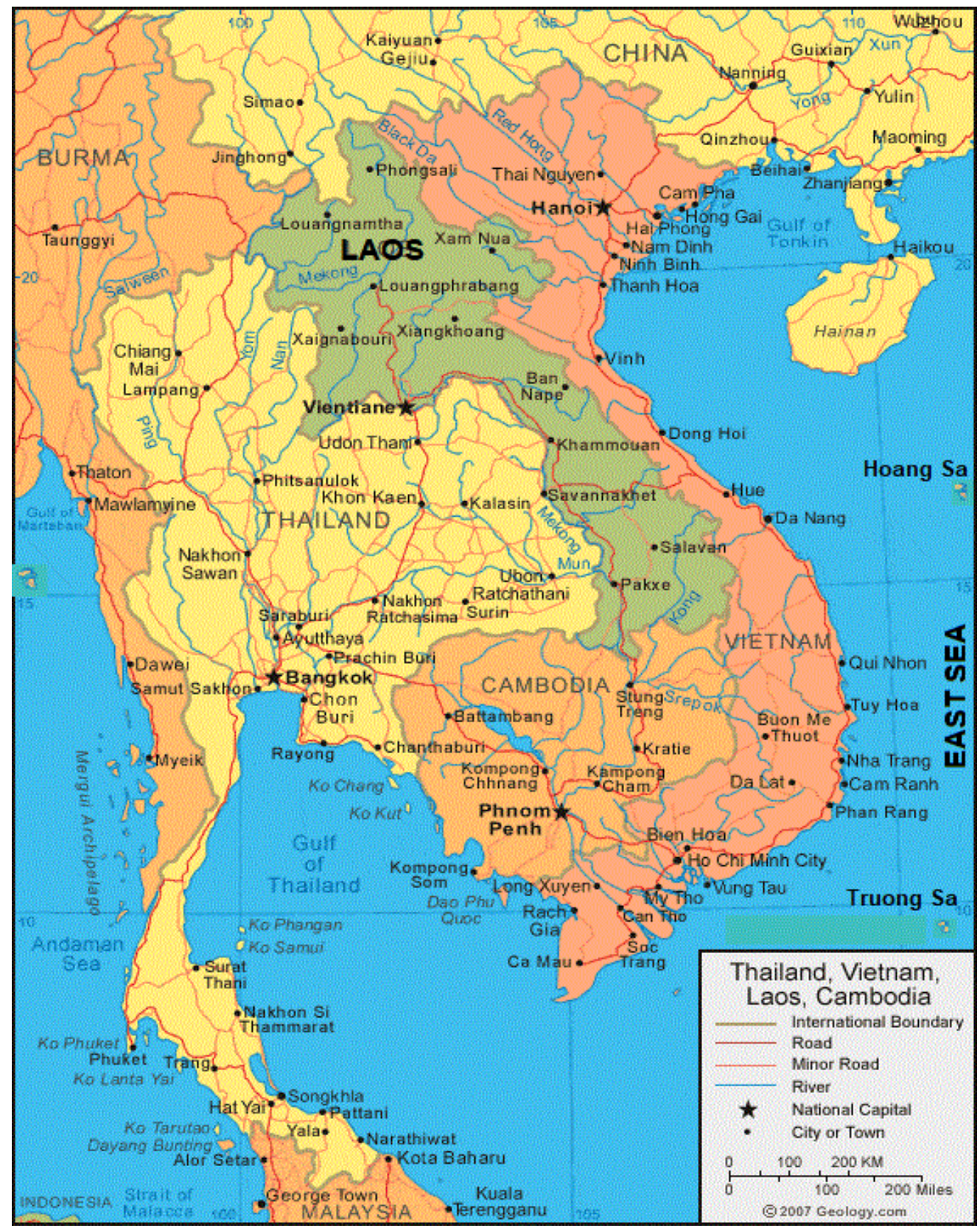

Hình 1. Bản đồ nước CHDCND Lào. (Nguồn: Internet).

như đất sét, bùn, cát, bitum,...; có màu sắc từ trắng đến màu tro, xanh nhạt, vàng và cả màu hồng sẫm, màu đen; có độ cứng 3 , khối lượng riêng $2.600 \div 2.800 \mathrm{~kg} / \mathrm{m}^{3}$, cường độ chịu nén $1700 \div 2600 \mathrm{~kg} / \mathrm{cm}^{2}$, độ hút nước $0,2 \div 0,5 \%$ (Thống kê hoạt động khai thác khoáng sản CHDCND Lào, 2019).

Khai thác đá vôi làm vật liệu xây dựng (VLXD) là hoạt động có nhiều nguy cơ gây tai nạn lao động (TNLĐ), bệnh nghề nghiệp (BNN) (Đàm Trọng Thắng và nnk., 2015; Bùi Xuân Nam và nnk., 2016).
Trong những năm gần đây, tình hình TNLĐ, BNN vẫn gia tăng và rất phức tạp, trong đó có nhiều vụ rất nghiêm trọng tại CHDCND Lào. Theo báo cáo của Bộ Lao động và Thương binh xã hội của CHDCND Lào, năm 2020 trên toàn quốc đã xảy ra 673 vụ TNLĐ làm 349 người bị chết, trong đó khai thác đá vôi VLXD chiếm trung bình 13,2\% số vụ TNLĐ chết người và $5,9 \%$ số người chết của toàn ngành công nghiệp (Báo cáo về tình hình khai thác các mỏ đá xuất ra nước ngoài của Sở Năng lượng và Mỏ, 2017). Các vụ tai nạn đặc biệt nghiêm trọng chủ 
yếu nằm ở khâu công nghệ khoan - nổ mìn như: nổ mìn làm đá văng, tạo sóng chấn động và sóng va đập không khí; nổ mìn không kiểm soát liên quan đến kỹ năng của thợ nổ mìn (Hình 2). TNLĐ do phương tiện gây ra chủ yếu liên quan đến người lao động vận hành xe tải, máy xúc, máy ủi, đầu đập thủy lực, máy khoan tự hành trong quá trình di chuyển hay làm việc.

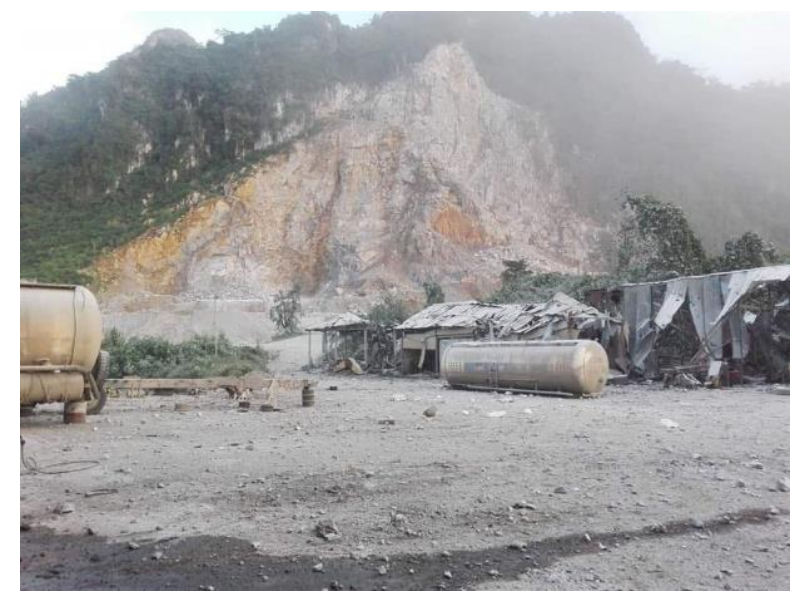

Hình 2. Vụ tai nạn tại mỏ đá vôi VLXD

Luangphang do tiêu hủy thuốc nổ sai quy phạm.

Các nguyên nhân chủ yếu được tập trung vào hai nhóm chính tại các tổ chức và các cấp doanh nghiệp là do người sử dụng lao động và người lao động, còn lại là do các yếu tố khách quan. Điều đó cho thấy nhận thức, kiến thức và ý thức tự giác chấp hành các quy định pháp luật về an toàn, vệ sinh lao động (ATVSLĐ) của người sử dụng lao động và người lao động còn nhiều thiếu sót. Tại các tổ chức và các doanh nghiệp, người sử dụng lao động và người lao động là lực lượng nòng cốt để thực hiện các công việc cũng như đảm bảo các vấn đề về an toàn lao động. Để nâng cao hiệu quả sản xuất và đảm bảo an toàn trong khai thác mỏ lộ thiên thì người lao động cần phải được đào tạo, bồi dưỡng kỹ năng điều hành sản xuất, kỹ năng nhận biết, xử lý nguy cơ và giải pháp thoát hiểm trong quá trình khai thác mỏ.

Ở Việt Nam đã có một số công trình khoa học nghiên cứu về quản lý, khai thác mỏ nói chung, an toàn và sức khỏe cho người lao động trong khai thác đá nói riêng:

Trong nghiên cứu của tác giả Bùi Xuân Nam và nnk, (2014) đã chỉ ra nhũng khái niệm cơ bản về ATVSLĐ, hệ thống pháp luật và quản lý nhà nước (QLNN) về ATVSLĐ, ATVSLĐ trong ngành mỏ; cung cấp kiến thức chuyên ngành và các kỹ thuật an toàn cần thiết, cũng như những nghiên cứu mới cập nhật ở trong nước và thế giới, có liên quan tới các khâu công nghệ chính trong khai thác lộ thiên, khai thác hầm lò, tuyển khoáng, cơ điện, cơ khí mỏ.

- Năm 2000, tác giả Nguyễn An Lương và cộng sự đã thực hiện đánh giá các yếu tố tác hại nghề nghiệp, tình hình ô nhiễm môi trường lao động, tình trạng sức khoẻ, bệnh tật, TNLĐ, BNN. Đề xuất được các biện pháp cơ bản để giám sát, dự phòng và xử lý các nguy cơ ô nhiễm môi trường lao động (Nguyễn An Lương, 2000).

- Năm 2010, tác giả Lê Vân Trình đã đi sâu nghiên cứu về môi trường lao động và quản lý môi trường lao động nói chung, với đặc điểm, nội dung và tiêu chí cụ thể nhằm đảm bảo quản lý tốt môi trường lao động cho người lao động (Lê Vân Trình, 2010).

- Năm 2013, tác giả Nguyễn Thắng Lợi đã nghiên cứu về quản lý nhà nước về ATSLĐ trong các doanh nghiệp khai thác đá xây dựng (DNKTĐXD) đảm bảo cho nền kinh tế tăng trưởng, phát triển kinh tế - xã hội gắn với khai thác hợp lý, hiệu quả, tiết kiệm tài nguyên thiên nhiên và BVMT. Đánh giá khách quan thấy rằng công tác QLNN về ATVSLĐ trong DNKTĐXD ở Việt Nam còn nhiều hạn chế, đó là: mô hình tổ chức QLNN về ATVSLĐ trong DNKTĐXD còn bất cập, chưa phù hợp; công tác quy hoạch, kế hoạch khai thác đá xây dựng chưa được quan tâm và chưa gắn với ATVSLĐ; việc xây dựng, ban hành và thực hiện pháp luật về ATVSLĐ trong DNKTĐXD còn thiếu và chậm; công tác thông tin, tuyên truyền, huấn luyện về ATVSLĐ còn yếu; công tác thanh tra, kiểm tra, ngăn ngừa xử lý vi phạm còn hạn chế (Nguyễn Thắng Lợi và nnk, 2013).

Trên thế giới đã có nhiều nghiên cứu về ATVSLĐ trong khai thác mỏ nói chung và khai thác đá VLXD nói riêng, trong đó có các nghiên cứu về các nguy cơ, rủi ro mất ATVSLĐ trong hoạt động khai thác đá VLXD và thuật toán nghiên cứu để hỗ trợ cho việc đánh giá rủi ro, xác định nguy cơ mất ATVSLĐ trong khai thác mỏ. Điển hình là các công trình như: M. Gulumian và nnk, (2006) đã nghiên cứu về đánh giá rủi ro trong lĩnh vực khai thác mỏ; Simon Thompson, BappScMinEng (1999), đã xây dựng tài liệu hướng dẫn về đánh giá rủi ro cho các mỏ. Ngoài ra, còn có một số tài liệu về đánh gái rủi ro, như: Sổ tay về đánh giá rủi ro trong mỏ, đối với các loại mỏ kim loại, lộ thiên và khai thác đá (Radosavljević, S. \& Radosavljević, M., 2009). 
- Năm 2007, J. Bennett (2007) đã nghiên cứu đưa ra mô hình hệ thống quản lý ATVSLĐ trong khai thác đá. Các tác giả đã nghiên cứu và đề xuất mô hình quản lý an toàn và sức khỏe nghề nghiệp trong các doanh nghiệp khai thác đá VLXD. Hệ thống quản lý an toàn và sức khỏe trong khai thác đá được giới thiệu trong Hình 3 . Từ Hình 3 , nhận thấy: để quản lý hiệu quả an toàn, sức khỏe của người lao động trong các doanh nghiệp hoạt động khai thác đá cần phải quản lý mang tính hệ thống cao, đảm bảo 5 nội dung: (i) Chiến lược và chính sách (hoạch định chiến lược và các chính sách phát triển ngành khai thác đá gắn với quản lý an toàn và sức khỏe); (ii) Lập kế hoạch (lập kế hoạch an toàn và sức khỏe trong sản xuất cụ thể); (iii) Vận hành hệ thống; (iv) Xem xét hệ thống; (v) Kiểm tra, giám sát và cải tiến (thực hiện kiểm tra, giám sát và cải tiến hoạt động đảm bảo ATVSLĐ trong khai thác đá).

- Năm 1996, Barbaga A. Plog đã đi sâu nghiên cứu về các yếu tố gây nguy hại cho người lao động trong môi trường sản xuất công nghiệp và cách thức phát hiện các yếu tố nguy hại đến sức khỏe, tính mạng của người tham gia lao động và môi trường nhằm đưa ra các biện pháp kiểm soát, giảm thiểu thiệt hại về sức khỏe và tính mạng của người lao động và bảo vệ môi trường (Barbara A. Plog, 1996).

- Tác giả Injae Lee đã có bản báo cáo vào năm 2006 về "Mô hình quản lý lao động Hàn Quốc: Bài học cho các nước đang phát triển”. Trong báo cáo này, đã chỉ ra tầm quan trọng của quản lý lao động tại Hàn Quốc đã góp phần phát triển kinh tế mà còn đẩy mạnh những quyền lợi chính đáng của người lao động. Bản báo cáo được chia làm 8 phần chính. Trong đó, phần thứ 7 đề cập tới chính sách ATVSLĐ và hệ thống bồi thường TNLĐ của Hàn Quốc (Injae Lee, 2003). Năm 1981, Luật An toàn sức khỏe công nghiệp của Hàn Quốc ra đời nhằm ngăn ngừa TNLĐ và BNN đang gia tăng.

\section{Hoạt động quản lý và khai thác các mỏ đá vôi VLXD tại CHDCND Lào}

\subsection{Quy mô và sản lưọng mỏ}

Số lượng các mỏ và điểm mỏ đá vôi VLXD đang được khai thác là khá lớn, tuy nhiên, số lượng các mỏ có công suất khai thác thiết kế từ $500.000 \div 300.000$ tấn/năm chiếm tỷ lệ không lớn, hầu hết là các mỏ khai thác đá vôi phục vụ nguyên liệu cho các nhà máy xi măng lớn. Ngoài ra có một số mỏ đá vôi khai thác làm nguyên liệu phục vụ cho ngành giao thông, phục vụ cho một số nhà máy xi măng nhỏ,... với công suất thiết kế 100.000 $\div 400.000$ tấn/năm và các mỏ có công suất thiết kế nhỏ dưới 300.000 tấn/năm (chiếm tỷ lệ tới 90\% trong tổng số các mỏ đang khai thác), phân bố hầu hết ở các tỉnh phía bắc như các tỉnh Luang Pha Bang, Xieng Khoang, Hoa Phan, Udom Xay, Xay Ya Bouli.

Hiện nay, hầu hết các mỏ đá vôi VLXD tại CHDCND Lào là do các tổ chức, cá nhân tham gia khai thác với nhiều mục đích khác nhau. Tuy nhiên, do vốn đầu tư hạn chế nên không có điều kiện đầu tư khai thác quy mô lớn. Một số khai thác nhỏ lẻ, manh mún, tố chức mang tính chất gia đình.

Bên cạnh đó, công tác khai thác đá vôi VLXD của một số tổ chức, cá nhân còn mang tính chất

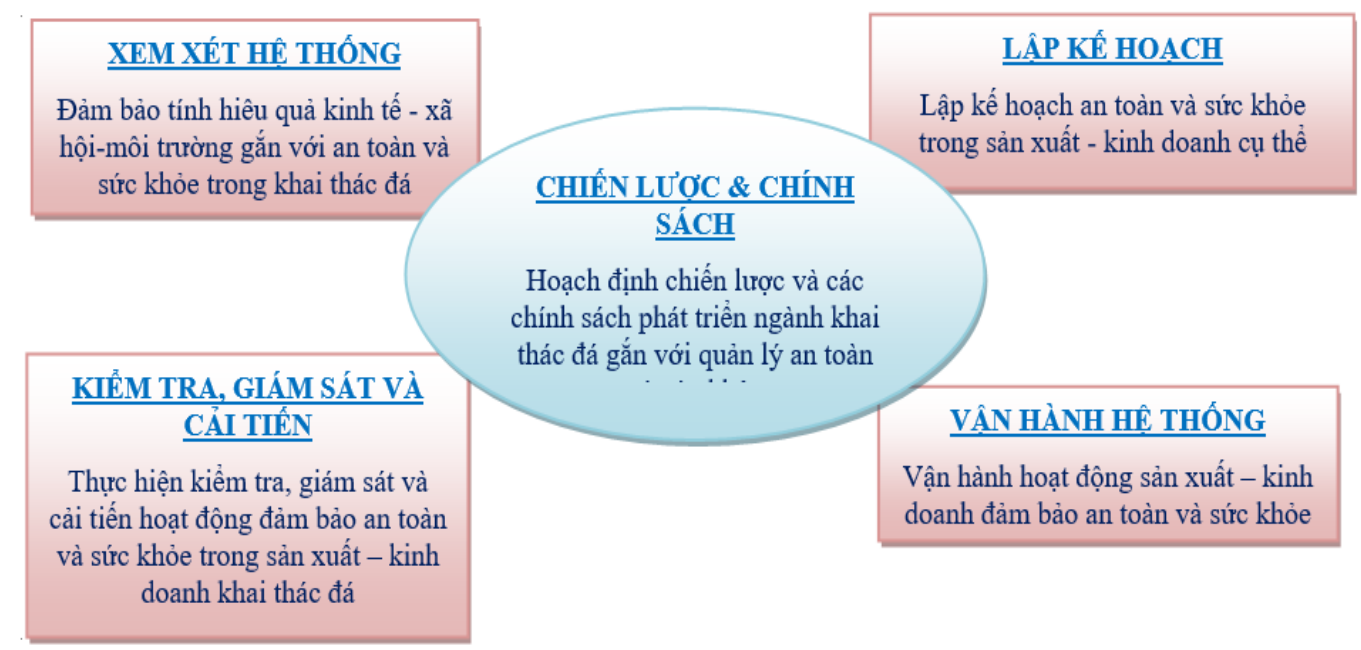

Hình 3. Mô hình quản lý an toàn và sức khỏe trong các doanh nghiệp khai thác đá VLXD (J. Bennett, 2007). 
tự do, không có thiết kế - quy hoạch, chưa tập hợp thành một ngành công nghiệp có chỉ đạo thống nhất; công nghệ khai thác còn lạc hậu. Nhìn chung, thiết bị khai thác của nhưng tổ chức, cá nhân này chưa đồng bộ, do nhiều nước sản xuất, rất khó khăn trong công tác sửa chữa, vận hành dẫn đến hạn chế về năng suất làm việc, không đảm bảo an toàn lao động và vệ sinh môi trường.

\subsection{Công nghệ và thiết bị khai thác}

Công nghệ khai thác được áp dụng cho các mỏ đá vôi VLXD bao gồm: (i) công nghệ khai thác khấu theo lớp đứng, cắt tầng nhỏ (khấu suốt); (ii) công nghệ khai thác khấu theo lớp xiên, chuyển tải bằng cơ giới; (iii) công nghệ khai thác khấu theo lớp bằng (hoặc lớp xiên) vận tải trực tiếp. Những mỏ thuộc nhóm này có công suất vừa và nhỏ, nhưng chiếm tỷ lệ khá lớn tại CHDCND Lào. Thiết bị hoạt động trên tầng công tác là máy khoan, các thiết bị khác là máy xúc, ô tô hoạt động ở chân tuyến (Hình 4). Thiết bị khai thác ở các mỏ này như sau:

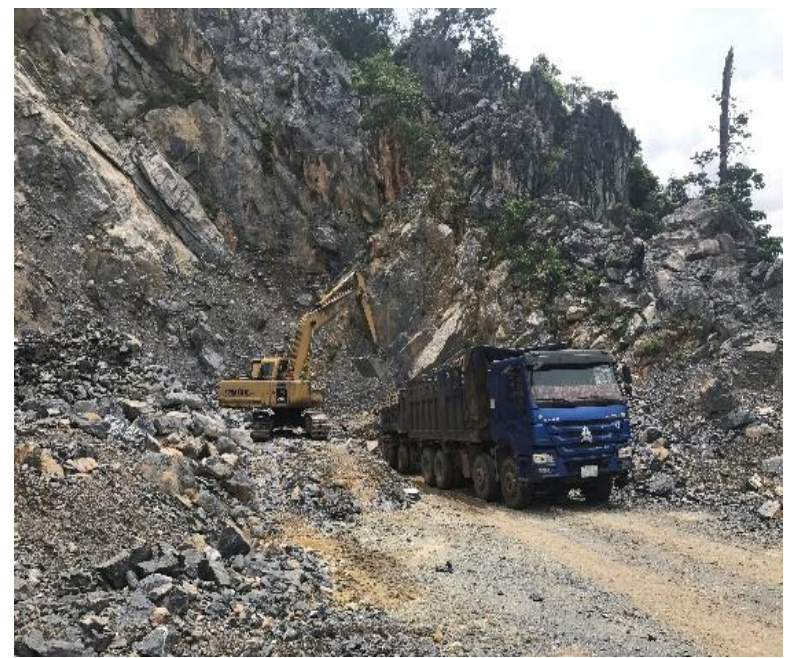

Hình 4. Khai thác đá vôi VLXD tại CHDCND Lào.

- Khâu khoan - nổ mìn: sử dụng máy khoan tay của Thụy Điển, Nhật Bản, Trung Quốc hoặc Liên Xô (cũ) sản xuất, có đường kính từ $32 \div 40 \mathrm{~mm}$. một số mỏ có sử dụng máy khoan BMK - 4, với số lượng không nhiều.

- Khâu xúc bốc: chủ yếu các mỏ sử dụng máy xúc thủy lực có dung tích $0,5 \div 2,0 \mathrm{~m}^{3}$ của Nhật Bản, Hàn Quốc, Trung Quốc sản xuất.

- Khâu vận tải: sử dụng ô tô tải trọng $5 \div 15$ tấn như ZIN, HINO, KpAZ - 256.

Ở các mỏ khai thác đá vôi VLXD, hầu như các mỏ nhỏ không xây dựng quy trình khoan và nổ mìn đầy đủ cho một vụ nổ. Chỉ ở một số mỏ có quy mô lớn và vừa mới có bảng quy định cụ thể về an toàn trong công tác khoan.

\subsection{Vấn đề quản lý an toàn trong công tác khoan - nổ mìn}

Nhìn chung việc chấp hành các quy định của pháp luật về an toàn lao động, vệ sinh lao động tại các doanh nghiệp hoạt động xây dựng và khai thác khoáng sản đã có sự chuyển biến theo chiều hướng tích cực. Tuy nhiên, còn rất nhiều doanh nghiệp chấp hành các quy định của pháp luật về AVSLĐ mang tính hình thức, đối phó, rất nhiều hành vi vi phạm các quy định của pháp luật ATVSLĐ đã được phát hiện. Hoạt động khai thác đá vôi VLXD trên địa bàn các tỉnh của nước CHDCND Lào còn nhiều doanh nghiệp vi phạm các hành vi như sau:

- Khai thác không đúng theo thiết kế được duyệt;

- Không tiến hành tạo tầng khai thác, cắt tầng theo quy định;

- Góc dốc ổn định bờ mỏ không đúng;

- Chưa lập hộ chiếu khoan - nổ mìn và chưa lập biện pháp an toàn cho người, thiết bị khi tiến hành khoan tại những nơi có nguy cơ tụt lở ở chân tầng, những nơi có địa hình cheo leo và chưa lập hộ chiếu xúc cụ thể cho từng máy xúc và thực hiện xúc theo hộ chiếu;

- Việc sử dụng, bảo quản vật liệu nổ công nghiệp (VLNCN) phục vụ khai thác đá cũng còn nhiều bất cập: nhiều đơn vị khai thác có điều kiện kỹ thuật yếu, trình độ nhân lực nổ mìn thấp, các kho thuốc nổ được cấp phép nhiều, nằm rải rác và phân tán.

- Việc xử lý những vi phạm gây mất an toàn lao động, vệ sinh lao động trong các mỏ đá vôi VLXD cũng còn nhiều hạn chế, như: các kết quả thanh tra, kiểm tra không được phúc tra, giám sát việc triển khai thực hiện của doanh nghiệp, mới xử phạt hành chính bằng tiền, do đó chưa ngăn ngừa được các vi phạm tái diễn.

- Về mô hình tổ chức bộ máy đảm bảo ATVSLĐ trong khai thác đá vôi VLXD: với cách thức tổ chức cấp phép như hiện tại đã có sự tham gia của các cơ quan QLNN như Bộ Năng lượng và Mỏ, Bộ Công chính, Bộ Công an và đặc biệt là Bộ Tài nguyên và Môi trường. Đây là những cơ quan quản lý đầu mối trong hoạt động khai thác tài nguyên đá vôi và đặc biệt là Bộ Quốc phòng - An ninh quản lý hoạt động chất nổ công nghiệp. Việc phân cấp quản lý cũng đã 
được thực hiện xuống các sở quản lý trực tiếp dưới địa phương.

- Việc quy hoạch tổng thể phát triển vật liệu xây dựng nói chung và khai thác đá vôi nói riêng theo từng giai đoạn đã góp phần quan trọng cho việc thực thi pháp luật được thống nhất và có định hướng rõ ràng. Quy hoạch sớm và tốt sẽ là tiền đề tốt cho doanh nghiệp khi thực hiện công tác an toàn. Doanh nghiệp khai hình thành đã biết mình cần phải làm gì và làm như thế nào để công tác an toàn nổ mìn được đảm bảo (Soukhanouvong, 2020).

\subsection{Nhũ̃ng nguyên nhân của các vi phạm TNLĐ trong hoạt động khoan - nổ mìn}

Thứ nhất, việc tiếp cận khoa học về công tác an toàn trong sử dụng VLNCN theo kinh nghiệm thế giới chưa được thực hiện triệt để làm cho vai trò, ý nghĩa của an toàn có những khác biệt, phức tạp hơn nhưng hiệu quả chưa cao, đặc biệt là quy trình thực hiện an toàn, xác định phạm vi an toàn, tham vấn cộng đồng, sử dụng báo cáo an toàn sau khi được phê duyệt.

Thứ hai, một số quy định trong hệ thống văn bản pháp luật về an toàn trong công tác khoan - nổ mìn không phù hợp với thực tiễn và khoa học, ví dụ trong chủ trương đầu tư (chưa rõ về phương pháp an toàn trong dự án); các quy định về việc lập lại kế hoạch khai thác cho trường hợp điều chỉnh công suất, công nghệ khoan - nổ mìn chưa rõ ràng; việc quy định về đánh giá tác động sức khỏe cộng đồng, xã hội áp dụng như nhau cho tất cả các loại hình dự án là không phù hợp và khó khả thi. Ngoài ra, một số quy định trong các Luật Đầu tư, Luật Xây dựng, Luật Bảo vệ môi trường, Luật Lao động và Phúc lợi xã hội còn thiếu tính đồng bộ.

Thứ ba, về hoạt động thẩm định thiết kế của dự án: an toàn, thiết kế của dự án quyết định nguồn tác động đến môi trường, trong khi đó, cơ quan quản lý nhà nước chỉ tham gia gópý kiến đối với thiết kế cơ sở của dự án, không có thẩm quyền phê duyệt. Thiết kế cơ sở và thiết kế chi tiết cho các bước tiếp theo của dự án do chính chủ đầu tư phê duyệt, do vậy trong một số trường hợp (đối với các chủ đầu tư có ý thức kém về bảo vệ an toàn), mức độ tin cậy về thiết kế của dự án có nhưng giới hạn nhất định. Đây chính là một trong những thách thức cho cơ quan quản lý nhà nước trong lĩnh vực khoan - nổ mìn nói riêng và hoạt động khai thác mỏ nói chung.

Thứ tư, không ít trường hợp vì sức ép tăng trưởng kinh tế, một số ngành, địa phương xem nhẹ vai trò “an toàn là công cụ quyết định các dự án đầu tư khai thác mỏ theo định hướng phát triển bền vũng".

Thứ năm, trong một số trường hợp, quá trình bảo vệ an toàn chưa đúng mức, chưa lường trước các vấn đề nhạy cảm, phức tạp của dự án sẽ nảy sinh.

Thứ sáu, đầu tư ngân sách cho công tác bảo vệ an toàn còn hạn chế: chưa có đủ kinh phí để xây dựng cơ sở dữ liệu về bảo vệ an toàn; các thông tin dữ liệu về thực trạng an toàn, các yếu tố kinh tế - xã hội trên phạm vi toàn quốc còn tản mạn, không đầy đủ và thiếu hệ thống; trong khi đó, đây là những nhóm thông tin rất quan trọng phục vụ cho đánh giá an toàn trong công tác.

\section{Phương pháp đánh giá rủi ro trong hoạt động khoan - nổ mìn tại các mỏ khai thác đá vôi VLXD}

Rủi ro (theo cách hiểu truyền thống) là những thiệt hại, mất mát, nguy hiểm hoặc là các yếu tố liên quan đến nguy hiểm, khó khăn hoặc không chắc chắn có thể xảy ra cho con người. Rủi ro (theo cách hiểu hiện đại) là sự bất trắc có thể đo lường được, vừa mang tính tính cực vừa mang tính tiêu cực. Rủi ro là sự kết hợp giữa khả năng xảy ra những mối nguy (xác suất xảy ra) và mức độ nghiêm trọng của tổn thương có thể. Mức độ rủi ro có thể chấp nhận được khi nằm trong giới hạn cho phép theo yêu cầu của luật định (bụi, tiếng ồn,... BNN nằm trong giới hạn cho phép).

Các quá trình hoạt động trên mỏ đá vôi VLXD tại CHDCND Lào cho thấy, các TNLĐ đều bắt nguồn từ các hành vi mất an toàn gây ra. Các hành vi mất an toàn trên mỏ có thể rất dễ nhận biết (hành vi mất an toàn trực tiếp) hoặc cũng rất khó nhận biết (hành vi mất an toàn gián tiếp). Các hành vi mất an toàn gồm các yếu tố cá nhân, nhận thức về rủi ro, chất lượng kém của thiết bị sẽ tạo ra môi trường trường mất an toàn. Môi trường mất an toàn này sẽ rất nguy hiểm nếu bị tác động bởi yếu tố khác như thời tiết, thiếu kinh nghiệm, làm tắt và vận hành sai quy trình. Do đó, để ngăn ngừa các tai nạn rủi ro, phải tiến hành đánh giá rủi ro giúp nhận diện đúng, đủ và rõ ràng các mối nguy hiểm.

Đánh giá rủi ro là quá trình tìm hiểu những rủi ro có thể và sẽ liên quan tới công việc chuẩn bị thực hiện, phải chỉ ra cụ thể những rủi ro có thể gặp. Xây dựng những biện pháp và thực thi công việc một 
cách nhất quán, an toàn nhất, nhằm tránh gây tai nạn cho người, hư hại tài sản, thiết bị và tổn thương môi trường. Công tác đánh giá rủi ro được tiến hành theo tiến trình như trong Hình 5.

\section{* Chia công việc thành tù̀ng bước nhỏ}

Phải chia nhỏ công việc sẽ tiến hành thành những bước thực hiện nhỏ hơn, theo trình tự trước sau. Các bước tiến hành thực sự rành rọt và liên quan cụ thể trực tiếp tới từng diễn biến cũng như mức độ nguy hiểm đang, sẽ và có thể xảy ra khi tiến hành công việc.

* Nhận dạng mối nguy hiểm liên quan tới tùng bước thực hiện

Bất cứ cái gì, điều gì có thể gây thương tích cho con người, làm hư hỏng tài sản và huỷ hoại môi trường đều là những mối nguy hiểm (Vu Nhu Van, 2007; Cục an toàn lao động, 2012). Các mối nguy hiểm có thể hiện hữu (mối nguy hiểm vật chất bao gồm vật dụng đồ dùng, dụng cụ máy móc) hoặc không hiện hữu (mối nguy hiểm đạo đức và tinh thần).

\section{* Đánh giá rủi ro}

Đánh giá rủi ro được tiến hành dựa trên tần suất (khả năng) xảy ra rủi ro và mức độ nghiêm trọng. Như vậy, rủi ro được tính toán theo công thức sau:
Rủi ro = Mức độ nghiêm trọng *tần suất xảy ra rủi ro.

Mức độ nghiêm trọng là xác định thiệt hại về con người: ước tính số người bị thiệt mạng, bị thương tích. Phải kể đến các chi phí y tế, sơ cứu ban đầu, chi phí chữa trị ngắn hạn và lâu dài, tiền công nghỉ ốm, chế độ,... Xác định thiệt hại về tài sản: ước tính thiệt hại về tài sản bị hư hỏng khi xảy ra tai nạn. Xác định thiệt hại về môi trường: phải đánh giá những tác động và thiệt hại nếu vụ tai nạn đó gây ảnh hưởng đến môi trường. Mức độ nguy hiểm được quy ước như trong Bảng 1.

* Các biện pháp kiểm soát rủi ro:

Để quản lý, kiểm soát được rủi ro trong hoạt động khai thác mỏ cần phải thực hiện lặp đi lặp lại theo chu trình như biểu diễn trong Hình 6 , bao gồm các bước chính: phân tích rủi ro, đánh giá rủi ro và kiểm soát rủi ro.

\section{4. Áp dụng phương pháp đánh giá rủi ro cho các mỏ đá vôi VLXD tại CHDCND Lào}

Để đánh giá rủi ro được tiến hành theo 2 phương pháp: đánh giá rủi ro định tính và định lượng (Bùi Xuân Nam, 2011; Nguyễn Sỹ Hội, 2001; Ha Tat Thang và nnk., 2012; Nguyễn Thị Toán, Hoàng Thị Minh Thuý, 2008).

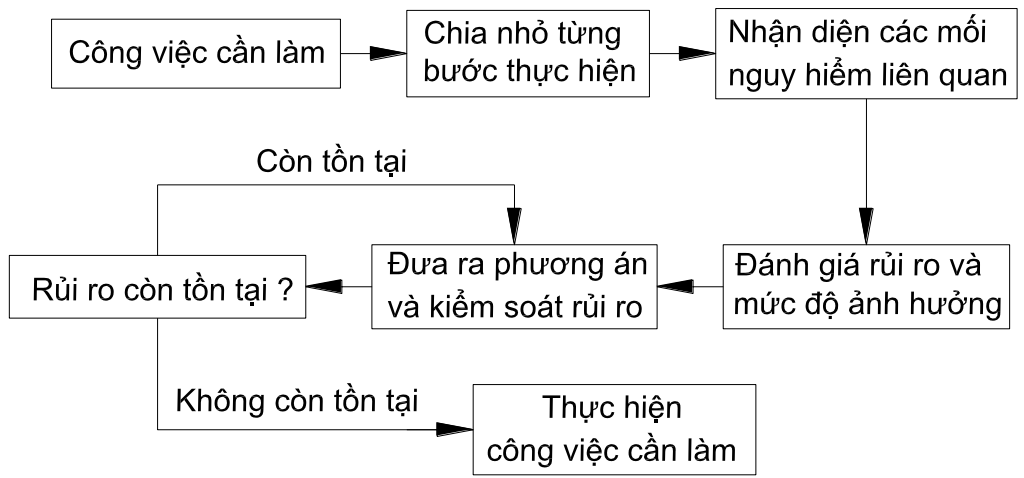

Hình 5. Tiến trình đánh giá rủi ro tai nạn lao động.

Bảng 1. Đánh giá hậu quả của các mối nguy hiểm trong công tác khoan - nổ mìn.

\begin{tabular}{|c|c|}
\hline Hậu quả & Mô tả \\
\hline Nhẹ & $\begin{array}{c}\text { Không chấn thương, chấn thương hoặc ốm đau chỉ yêu cầu sơ cứu (bao gồm các vết đứt } \\
\text { và trầy xước nhỏ, sưng tấy, ốm đau với lo lắng tạm thời) }\end{array}$ \\
\hline Trung bình & $\begin{array}{c}\text { Chấn thương yêu cầu điều trị y tế hoặc ốm đau dẫn đến ốm yếu tàn tật (bao gồm vết } \\
\text { rách, bỏng, bong gân, gãy nhỏ, viêm da, điếc,...) }\end{array}$ \\
\hline Nặng & $\begin{array}{c}\text { Chết người, chấn thương trầm trọng hoặc bệnh nghề nghiệp có thể làm chết người (bao } \\
\text { gồm cụt chân tay, gãy xương lớn, đa chấn thương, ung thư nghề nghiệp, nhiễm độc cấp } \\
\text { tính và chết người) }\end{array}$ \\
\hline
\end{tabular}


Bảng 2. Các cấp độ của các mối nguy hiểm trong công tác khoan - nổ mìn.

\begin{tabular}{|c|l|l|}
\hline Cấp độ & \multicolumn{1}{|c|}{ Mô tả } & \multicolumn{1}{c|}{ Mô tả } \\
\hline A & Rất cao & Tử vong \\
\hline B & Cao & Thương tật nghiêm trọng vĩnh viễn \\
\hline C & Trung bình & Cần điều trị y tế, mất ngày công \\
\hline D & Thấp & Điều trị y tế, sơ cứu (có thể quay lại làm việc) \\
\hline E & Không đáng kể & Điều trị sơ cứu (có thể quay lại làm việc) \\
\hline
\end{tabular}

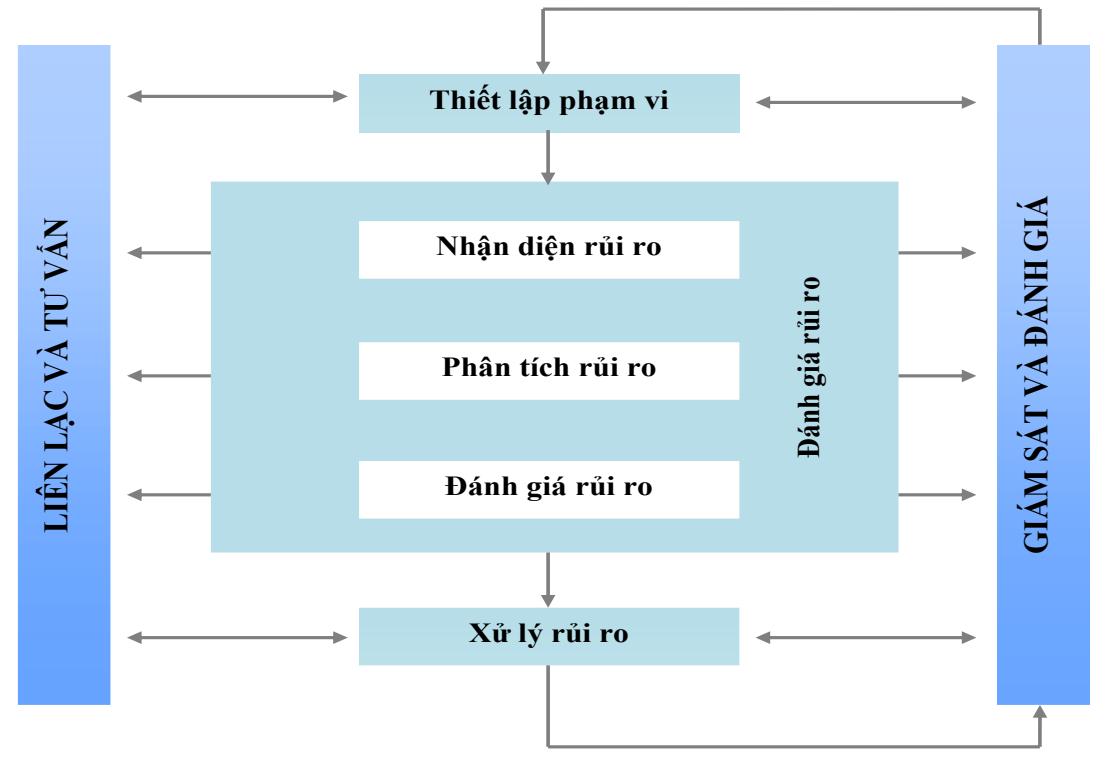

Hình 6. Sơ đồ quản lý rủi ro ATVSLĐ trong các mỏ đá VLXD.

Bảng 3. Xác định khả năng xuất hiện của tai nạn, sự cố tù mối nguy hiểm trong công tác khoan và nổmìn.

\begin{tabular}{|c|l|}
\hline Cấp độ & \multicolumn{1}{|c|}{ Mô tả } \\
\hline 1 & Chắc chắn hoặc gần như chắc chắn \\
\hline 2 & Có khả năng xảy ra \\
\hline 3 & Có thể xảy ra \\
\hline 4 & Ít khi xảy ra \\
\hline 5 & Hiếm khi xảy ra \\
\hline
\end{tabular}

Phương pháp đánh giá rủi ro định tính được sử dụng trong những trường hợp đơn giản, quy mô nhỏ, đánh giá rủi ro tại nơi làm việc với kết quả đưa ra mức rủi ro thấp, trung bình, cao được xác định bằng ma trận 3x3 (Bảng 4) hoặc thấp, trung bình, cao, rất cao xác định bằng ma trận $5 \times 5$ (Bảng 5).

Bảng 4. Ma trận xác định múc rủi ro 3x3.

\begin{tabular}{|l|c|c|c|}
\hline $\begin{array}{c}\text { Khả năng xảy } \\
\text { ra hậu quả }\end{array}$ & Hiếm khi & $\begin{array}{c}\text { Thỉnh } \\
\text { thoảng }\end{array}$ & $\begin{array}{c}\text { Thường } \\
\text { xuyên }\end{array}$ \\
\hline Nặng & Trung bình & Cao & Cao \\
\hline Trung bình & Thấp & Trung bình & Cao \\
\hline Nhẹ & Thấp & Thấp & Trung bình \\
\hline
\end{tabular}

Bảng 5. Ma trận xác định mức rủi ro 5x5.

\begin{tabular}{|c|c|c|c|c|c|}
\hline \multirow{2}{*}{$\begin{array}{c}\text { Khả năng } \\
\text { xảy ra }\end{array}$} & \multicolumn{5}{|c|}{ Cấp độ nguy hiểm } \\
\hline 1 & Rất cao & Rất cao & Cực cao & Cao & Cao \\
\hline 2 & Rất cao & Rất cao & Cao & Cao & $\begin{array}{c}\text { Trung } \\
\text { bình }\end{array}$ \\
\hline 3 & Rất cao & Rất cao & Cao & $\begin{array}{c}\text { Trung } \\
\text { bình }\end{array}$ & Thấp \\
\hline 4 & Rất cao & Cao & $\begin{array}{c}\text { Trung } \\
\text { bình }\end{array}$ & Thấp & Thấp \\
\hline 5 & Cao & Cao & $\begin{array}{c}\text { Trung } \\
\text { bình }\end{array}$ & Thấp & Thấp \\
\hline
\end{tabular}

- Rủi ro rất cao: không chấp nhận được, phải dừng hoạt động và áp dụng bổ sung các biện pháp để giảm thiểu rủi ro;

- Rủi ro cao: phải được giảm thiểu xuống mức thấp nhất phù hợp thực tế. Cần cân nhắc giảm rủi ro tới mức nếu áp dụng thêm các biện pháp giảm rủi ro thì sẽ không hiệu quả hoặc thiếu thực tế.

- Rủi ro trung bình: chấp nhận được. 
Các biện pháp giảm rủi ro hiện hữu đã đầy đủ, cho phép tiếp tục hoạt động và không cần phải đưa ra bất kỳ biện pháp bổ sung nào.

- Rủi ro thấp: chấp nhận rộng rãi. Các biện pháp giảm rủi ro hiện hữu đã đầy đủ, cho phép tiếp tục hoạt động và không cần phải đưa ra bất kỳ biện pháp bổ sung nào.

Đánh giá rủi ro định lượng thường được sử dụng để đánh giá rủi ro công nghệ, các trường hợp phức tạp, quy mô lớn và có đủ dữ liệu để thực hiện đánh giá rủi ro định lượng. Kết quả đưa ra là những con số, để so sánh với mức rủi ro có thể chấp nhận được theo quy định của quy chuẩn.

Trong khai thác đá vôi VLXD, các rủi ro về tai nạn lao động luôn tiềm ẩn trong các khâu, các quy trình sản xuất của mỏ.

Nhìn chung, các khâu công đoạn chính trong hoạt động khai thác mỏ đá vôi VLXD gồm: chuẩn bị đất đá khoan - nổ mìn; công tác xúc bốc; công tác vận tải; công tác nghiền sàng đá (Đỗ Trần Hải và nnk, 2017; Nguyễn Thắng Lợi và nnk, 2011).

Trên thực tế sản xuất tại các mỏ đá vôi VLXD ở CHDCND Lào thì khâu chuẩn bị đất đá chủ yếu bằng phương pháp khoan - nổ mìn và đây cũng là công đoạn xảy ra nhiều nguy cơ tai nạn nhất. Do đó, tiến hành đánh giá rủi ro về tai nạn lao động trong khai thác mỏ đá vôi VLXD cần chia nhỏ các khâu công đoạn chính thành các công đoạn nhỏ hơn theo trật tự trước sau:

Cần đặt ra một số câu hỏi trong quá trình phân tích xác định mối nguy hiểm như:

+ Công nghệ khai thác nào áp dụng cho công đoạn này?

+ Các thiết bị khai thác nào liên quan tới quá trình thực hiện?

+ Điều kiện thời gian, thời tiết có ảnh hưởng gì đến quá trình thực thực hiện?

+ Những mối nguy hiểm nào đang hiện hữu tại khu vực sẽ tiến hành công việc?

+ Những mối nguy hiểm nào có thể xảy ra khi công việc đang tiến hành?

+ Những mối nguy hiểm tiềm ẩn nào có thể xuất hiện khi bị tác động bởi nhưng hành vi có liên quan?

Trên cơ sở đánh giá được hậu quả của các mối nguy hiểm, các cấp độ của các mối nguy hiểm và xác định được khả năng xuất hiện của tai nạn, sự cố từ mối nguy hiểm trong công tác khoan và nổ mìn cho phép xây dựng bảng ma trận đánh giá rủi ro trong công tác khoan - nổ mìn trên các mỏ đá VLXD tại
CHDCND Lào (Bảng 6).

Từ Bảng 6 cho phép đánh giá được hậu quả của các mối nguy hiểm, các cấp độ của các mối nguy hiểm và xác định được khả năng xuất hiện của tai nạn, sự cố từ mối nguy hiểm trong công tác khoan nổ mìn. Ví dụ với công tác khoan thì hoạt động di chuyển, vận hành máy khoan trên tầng sẽ có 3 mối nguy hiểm hiện hữu có thể xảy ra và mối nguy hiểm do đá từ trên cao rơi xuống máy khoan là có khả năng xảy ra cao nhất $(2,3,4)$ và có cấp độ nguy hiểm cao nhất $(\mathrm{A}, \mathrm{B})$, hậu quả có thể xảy ra nguy hiểm tai nạn cao đến từ vong $(2,3)$. Từ đó đã đề xuất được các biện pháp hạn chế, giảm thiểu rủi ro, đó là: trang bị đủ bảo hộ lao động; xử lý trước đá treo, đá mồ côi trên cao; giữ khoảng cách an toàn và xây dựng rào chắn nơi có nguy cơ cao về đá rơi.

\section{Kết luận}

Đá vôi làm VLXD ở nước CHDCND Lào rất phong phú, được phân bố trên nhiều vùng, miền của đất nước. Việc khai thác đá vôi làm VLXD đã góp phần tích cực vào việc xây dựng đất nước. Bên cạnh mặt tích cực đáp ứng được nhu cầu tiêu dùng tại chỗ, hiện nay tại CHDCND Lào, còn có việc khai thác bừa bãi, trái phép, sử dụng không hợp lý, gây lãng phí tài nguyên khoáng sản rất lớn, tiềm ẩn nhiều nguy cơ mất an toàn lao động và đặc biệt là gây ô nhiễm môi trường. Nhiều có sở đã đầu tư khai thác tràn lan, thiếu quy hoạch và kế hoạch thống nhất dẫn đến tình trạng dễ làm khó bỏ. Trong khai thác, các quy phạm khai thác, quy phạm an toàn, quy phạm sử dụng vật liệu nổ,... không được tôn trọng và thực hiện nghiêm. Một số vụ tai nạn gây chết người do mất an toàn lao động; việc bảo đảm môi trường trong quá trình khai thác, chế biến đá của các mỏ đá vôi VLXD còn yếu, thiếu đồng bộ và chưa hiệu quả. Nghiên cứu này đi sâu phân tích thực trạng công tác khoan - nổ mìn tại các mỏ đá vôi VLXD của quốc gia này, từ đó đề xuất xây dựng phương pháp đánh giá nguy cơ rủi ro, mất an toàn trong hoạt động khoan - nổ mìn tại các mỏ khai thác đá vôi VLXD bằng các bảng ma trận đánh giá rủi ro nhằm phục vụ hiệu quả cho công tác quản lý và an toàn khai thác tại nước CHDCND Lào. Đây là phương pháp đánh giá hiện đại, đã được triển khai áp dụng cho nhiều ngành, nhiều lĩnh vực. Qua việc đánh giá rủi ro trong khai thác mỏ đá vôi VLXD giúp phát hiện các mối nguy hiểm tiềm tàng trong hoạt động khai thác, nhất là hoạt động khoan - nổ mìn có sử dụng VLNCN cần khảo sát tần suất và mức độ 
Bảng 6. Ma trận đánh giá rủi ro trong công tác khoan - nổ mìn trên các mỏ đá vôi VLXD tại CHDCND Lào.

\begin{tabular}{|c|c|c|c|c|c|c|c|}
\hline \multirow[b]{2}{*}{ TT } & \multirow[b]{2}{*}{$\begin{array}{l}\text { Quá } \\
\text { trình }\end{array}$} & \multirow[b]{2}{*}{ Hoạt động } & \multirow[b]{2}{*}{$\begin{array}{c}\text { Mối } \\
\text { nguy hiểm }\end{array}$} & \multicolumn{3}{|c|}{ Đánh giá rủi ro } & \multirow[b]{2}{*}{ Biện pháp hạn chế, giảm thiểu rủi ro } \\
\hline & & & & $\begin{array}{c}\text { Đánh } \\
\text { giá hậu } \\
\text { quả }\end{array}$ & \begin{tabular}{|} 
Cấp độ của \\
các mối \\
nguy hiểm
\end{tabular} & $\begin{array}{l}\text { Khả năng } \\
\text { xuất hiện }\end{array}$ & \\
\hline \multirow{3}{*}{1} & \multirow{3}{*}{ Khoan } & \multirow{3}{*}{$\begin{array}{c}\text { Di chuyển, } \\
\text { vận hành } \\
\text { máy } \\
\text { khoan trên } \\
\text { tầng }\end{array}$} & $\begin{array}{l}\text { Sạt lở bờ tầng; } \\
\text { nguy cơ trượt } \\
\text { ngã; Lật máy }\end{array}$ & 3 & A, B & 4,5 & $\begin{array}{l}\text { Mặt tầng đặt máy khoan phải đủ rộng và } \\
\text { ôn định. Không di chuyển và đặt máy sát } \\
\text { mép tầng và chân tầng. Máy khoan di } \\
\text { chuyển vuông góc mép tầng. }\end{array}$ \\
\hline & & & $\begin{array}{l}\text { Gãy, mất mũi } \\
\text { khoan, kẹt } \\
\text { chòong khoan }\end{array}$ & 2 & $\mathrm{~B}, \mathrm{C}$ & 2,3 & $\begin{array}{l}\text { Điều khiển tốc độ khoan phù hợp theo } \\
\text { điều kiện địa chất thủy văn, địa chất công } \\
\text { trình cụ thể của khu vực khoan. }\end{array}$ \\
\hline & & & Đá rơi & 2,3 & A, B & $2,3,4$ & $\begin{array}{l}\text { Trang bị đủ bảo hộ lao động; Xử lý trước } \\
\text { đá treo, đá mồ côi trên cao; Giưu khoảng } \\
\text { cách an toàn và xây dựng rào chắn nơi có } \\
\text { nguy cơ cao về đá rơi. }\end{array}$ \\
\hline \multirow{5}{*}{2} & \multirow{5}{*}{$\begin{array}{l}\text { Máy } \\
\text { nén } \\
\text { khí }\end{array}$} & \multirow{5}{*}{$\begin{array}{l}\text { Di chuyển, } \\
\text { vận hành } \\
\text { máy nén } \\
\text { khí }\end{array}$} & $\begin{array}{l}\text { Nguy hiểm về } \\
\text { nguồn điện }\end{array}$ & 2,3 & $\mathrm{~B}, \mathrm{C}$ & 3,4 & $\begin{array}{l}\text { Luôn chắc chắn rằng nguồn điện đã được } \\
\text { ngắt ra khỏi máy. Không chạm tay vào } \\
\text { những bộ phận hay bị hở điện như dây } \\
\text { mát. Vận hành máy trong điều kiện khô } \\
\text { ráo, thoáng mát. }\end{array}$ \\
\hline & & & $\begin{array}{l}\text { Nguy hiểm với } \\
\text { dòng khí nén áp } \\
\text { suất cao }\end{array}$ & 1,2 & $\mathrm{~B}, \mathrm{C}$ & 3,4 & $\begin{array}{l}\text { Không di chuyển máy nén khí, bình khí } \\
\text { khi chưa xả khí nén trong bình. Tháo máy } \\
\text { nén khỏi bình khí trước khi tiến hành sửa } \\
\text { chữa. Khi xả khí nên xả từ từ, đúng quy } \\
\text { trình, không được xả trực tiếp. }\end{array}$ \\
\hline & & & $\begin{array}{c}\text { Nguy cơ cháy } \\
\text { nổ }\end{array}$ & 2,3 & $\mathrm{~B}, \mathrm{C}$ & & Luôn kiểm tra điện áp vận hành của máy \\
\hline & & & Nguy cơ bị bỏng & 2,3 & $\mathrm{~B}, \mathrm{C}$ & 3,4 & $\begin{array}{l}\text { Mặc quần áo bảo hộ lao động cũng như có } \\
\text { chế độ kiểm tra, bảo dương, đại tu máy } \\
\text { nén khí định kỳ để phát hiện hỏng hóc và } \\
\text { sứa chữa cáng sớm càng tốt. }\end{array}$ \\
\hline & & & Đá roi & 2,3 & A, B & 3,4 & $\begin{array}{l}\text { Trang bị đủ bảo hộ lao động; Xử lý trước } \\
\text { đá treo, đá mồi côi trên cao; Không di } \\
\text { chuyển máy nén khí trong tuyến đang } \\
\text { khoan của máy khoan phía trên. }\end{array}$ \\
\hline \multirow{3}{*}{3} & \multirow{3}{*}{$\begin{array}{l}\text { Nổ } \\
\text { mìn }\end{array}$} & $\begin{array}{l}\text { Bảo quản, } \\
\text { vận } \\
\text { chuyển, } \\
\text { thử } \\
\text { VLNCN }\end{array}$ & $\begin{array}{l}\text { Giảm chất } \\
\text { lượng VLNCN, } \\
\text { tự nổ }\end{array}$ & 2,3 & C, D & 4,5 & $\begin{array}{l}\text { Hạn chết các kho mìn tư nhân, tập trung } \\
\text { các đầu mối vận chuyển VLNCN trực tiếp } \\
\text { từ kho chính đến nơi sử dụng VLNCN; } \\
\text { Tuân thủ khoảng cách an toàn khi làm } \\
\text { việc. }\end{array}$ \\
\hline & & \begin{tabular}{|c|} 
Nạp thuốc \\
nổ, nạp \\
bua; Đấu \\
ghép \\
mạng nổ. \\
\end{tabular} & \begin{tabular}{|} 
Công nhân \\
trượt ngã từ \\
trên cao; Đá rơi; \\
nổ kíp; Sét đánh \\
trúng bãi mìn. \\
\end{tabular} & 3,4 & $A, B, C$ & 3,4 & $\begin{array}{l}\text { Tuân thủ khoảng cách an toàn khi làm } \\
\text { việc; Tuân thủ đúng nổ mìn hộ chiếu nổ } \\
\text { mìn và biện pháp an toàn đã được phê } \\
\text { duyệt. }\end{array}$ \\
\hline & & $\begin{array}{c}\text { Nổ mìn; } \\
\text { Xư lý mìn } \\
\text { câm }\end{array}$ & $\begin{array}{c}\text { Sóng chấn động, } \\
\text { sóng đập không } \\
\begin{array}{c}\text { khí, đá văng, } \\
\text { bụi. }\end{array}\end{array}$ & $1,2,3$ & $\mathrm{~B}, \mathrm{C}$ & 1,2 & $\begin{array}{l}\text { Cảnh giới an toàn trước và sau vư nổ; } \\
\text { Tuân thủ đúng nổ mìn hộ chiếu nổ mìn và } \\
\text { biện pháp an toàn đã được phê duyệt. }\end{array}$ \\
\hline
\end{tabular}


nghiêm trọng về tai nạn. Từ đó, xác định mức rủi ro nhất định cho các mối nguy hiểm trong từng công đoạn sản xuất. Như vậy, giúp ta nhận biến mối nguy hiểm nào, trong công đoạn nào có mức độ rủi ro cao nhất mà có các biện pháp phù hợp để hạn chế tai nạn lao động gây ra trong hoạt động khoan - nổ mìn trên các mỏ đá vôi VLXD tại CHDCND Lào.

Để tăng hiệu quả hoạt động khai thác và giảm rủi ro về tai nạn lao động trong hoạt động nổ mìn khai thác đá vôi VLXD, cần thiết thực hiện một số đề xuất:

- Cần hoàn chỉnh xây dựng các văn bản pháp quy để đưa phương pháp đánh giá rủi ro vào áp dụng rộng rãi trong thực tế sản xuất, đưa việc đánh giá và kiểm soát rủi ro vào quy phạm kỹ thuật an toàn trong khai thác mỏ lộ thiên và các quy phạm an toàn trong sử dụng VLNCN.

- Xây dựng quy trình huấn luyện, đào tạo chuyên nghiệp để nâng cao nhận thức cho người lao động và người sử dụng lao động về vấn đề "An toàn và sức khỏe nghề nghiệp" trong khai thác mỏ lộ thiên.

- Cần triển khai đánh giá rủi ro cho tất cả các dạng mỏ cụ thể theo công nghệ khai thác mỏ lộ thiên cụ thể. Khi xác định mức độ rủi ro cho từng công đoạn sản xuất cần có bảng ma trận khuyến cáo cho các mối nguy hiểm về rủi ro cao.

\section{6. Đóng góp của các tác giả}

Trần Quang Hiếu - lên đề cương, đọc và chỉnh sửa bản thảo bài báo; Phonepaserth soukhanouvong - viết bản thảo bài báo; Lê Thị Thu Hoa, Lê Quí Thảo và Đỗ Ngọc Hoàn - phân tích, kết luận.

\section{Tài liệu tham khảo}

Báo cáo về tình hình khai thác các mỏ đá xuất ra nước ngoài của trưởng sở năng lượng và mỏ, số 1504 , ngày 10 tháng 10 năm 2017.

Barbara A. Plog. (1996). Fundamentals of industrial hygiene. Occupational safety and health series. National Safety Council (U.S.).

Bùi Xuân Nam. (2011). Giáo trình an toàn vệ sinh lao động trong các trường Cao đẳng và Đại học. Đề tài cấp Bộ.

Bùi Xuân Nam (chủ biên). (2014). An toàn và vệ sinh lao động trong ngành Mỏ. Nhà xuất bản Khoa học Tự nhiên và Công nghệ, Hà Nội.
Bùi Xuân Nam, Đặng Vũ Chí, Hoàng Tuấn Chung, Nguyễn Đức Khoát, Nhữ Thị Kim Dung. (2016). An toàn, vệ sinh lao động (dùng cho các trường trung cấp chuyên nghiệp nhóm ngành công nghệ kỹ thuật Mỏ - Địa chất). Nhà xuất bản Đại học Sư phạm, Hà Nội, 2016.

Cục An toàn lao động. (2012). Nghiên cúu thực trạng thực hiện chính sách, pháp luạt về an toan lao động trong hoat động khai thac đá. Báo cáo của Ban quản lý dự án RAS 12/50M/JPN.

Đàm Trọng Thắng, Bùi Xuân Nam, Trần Quang Hiếu. (2015). Nổ mìn trong ngành mỏ và công trình. Nhà xuất bản Khoa học Tự nhiên và Công nghệ, Hà Nội, 454 trang.

Đỗ Trần Hai, Phạm Quốc Quân (2017). Phương pháp phân loại chất lượng vệ sinh môi trường lao động và cấp độ rủi ro sức khỏe nghề nghiệp do các yếu tố môi trường lao động gây ra, Tạp chí Bảo hộ lao động, N1\&2/2017.

Ha Tat Thang, Nguyen Anh Tho, Pham Trung Thong, Pham Van Viet. (2012). Occupational safety in mining in Viet Nam. Proceedings of the 2nd international conference on advances in mining and tunneling, Ha Noi - Viet Nam.

Injae Lee, B. - H. and D. - B. Kim (2003). Union effect on the use of contingent workers. (in Korean), Paper presented at the 1st Academic Conference on the Workplace Panel Survey held by the Korea Labor Institute.

J. Bennett. (2007). Mô hình hệ thống quản lý ATVSLĐ trong khai thác đá (Quarry health and safety management system), Guidebook of the University of Queensland, Brisbane, Australia.

Lê Vân Trình, (2010). Nghiên cứu về môi trường lao động và quản lý môi trường lao động.

M. Gulumian, P.J. A. Borm, V. Vallyathan, V. Castranova, K. Donaldson, G. Nelson, J. Murray. (2006). Mechanistically identified suitable biomarkers of exposure, effect, and susceptibility for silicosis and coal - worker's pneumoconiosis: a comprehensive review.

Nguyễn An Lương. (2000). Báo cáo tổng kết nhiệm vu 213/08/NV - DA4 thuộc hoạt động 1. Dự án 4 , Chương trình quốc gia về ATLĐ, VSLĐ, Viện nghiên cứu KHKT Bảo hộ lao động. 
Nguyễn Sỹ Hội. (2001). Bài giảng kỹ thuật an toàn khai thác mỏ lộ thiên. Trường Đại học Mỏ - Địa chất Hà Nội.

Nguyen Thang Lơi. (2011). Nghiên cứu và áp dụng thử mô hình quản lý rủi ro trong sản xuất nhằm góp phàn nâng cao hiệu quả công tác an toàn vệ sinh lao động ở các cơ sở sản xuất vừa và nhỏ, Báo cáo tổng kết đề tài cấp Bộ, mã số 209/13/TLĐ, Viện nghiên cứu KHKT Bảo hộ lao động.

Nguyễn Thắng Lợi (Cb.). (2013). Xây dựng cơ sở khoa học để nâng cao hiệu quả quản lý ATVSLĐ trong các doanh nghiệp khai thác đá để làm vật liệu xây dựng.

Nguyễn Thị Toan, Hoàng Thị Minh Thủy, (2008). Nghiên cứu bệnh điếc nghề nghiệp và ảnh hưởng của tiếng ồn đến sức khoẻ công nhân khai thác đá, Tạp chí Bảo hộ lao động, 6/2008.

QCVN: 05/2012/BLĐTBXH. (2012). Quy chuẩn kỹ thuật quốc gia về an toàn lao động trong khai thác và chế biến đá.
Radosavljević, S. \& Radosavljević, M. (2009). Risk assessment in mining industry - Apply management. Serbian Journal of Management, 4(1), 91 - 104. ISSN 1452 - 4864.

Simon Thompson, BappScMinEng. (1999). AssDipOH\&S, FAUSIMM. Simon Thompson \& Partners safety, while at the same time actively identifying and controlling risks at the mine.

Soukhanouvong. (2019). Tổng quan về các quản công cụ quản lý nhà nước đối với công tác an toàn trong khai thác đá vôi của nước CHDCND Lào

Soukhanouvong. (2020). Nghiên cứu hiện trạng khai thác tài các mỏ đá vật liệu xây dựng trên địa bàn tỉnh Bolikhamxay - CHDCND Lào và đề xuất các giải pháp khai thác hợp lý nhằm bảo vệ môi trường và phát triển bền vững.

Thống kê hoạt động khai thác khoáng sản tháng 8/2019, CHDCND Lào.

$\mathrm{Vu}$ Nhu Van. (2007). Occupational Safety in Mining in Viet Nam. MOLISA/ISSA Conference, Ha Noi. 